\#176 Eficácia das normas cefalométricas na previsão do tratamento ortodôntico-cirúrgico

Mariana Latas Rodrigues*, Inês Alexandre Neves Francisco, Francisco Fernandes do Vale

Faculdade de Medicina da Universidade de Coimbra

Objetivos: O objetivo deste estudo foi verificar se existem diferenças no perfil dos tecidos moles entre os indivíduos submetidos a tratamento ortodôntico-cirúrgico e os indivíduos pertencentes a uma população esteticamente ideal. Materiais e métodos: Após aplicação dos critérios de inclusão e exclusão previamente definidos para este estudo, foram selecionados de um total de 578 indivíduos portugueses de raça caucasiana e de ambos os géneros: 55 indivíduos para integrar um grupo de controlo (população ideal), com idade média de 22.6 anos e, 20 indivíduos com idade média de 22.75 anos que realizaram com sucesso, o tratamento ortodôntico cirúrgico para correção da má-oclusão de classe III. A análise cefalométrica das telerradiografias de perfil foi realizada no programa Dolphin Imaging Software, versão 8.0.6.12 (Dolphin Imaging Systems Inc., USA) com recurso à análise disponibilizada no atlas de cefalometria clínica de Miyashita and Dixon (1996). Para análise estatística, recorreu-se ao teste t-Student e utilizou-se um nível de significância de 5\% e intervalo de confiança de 95\%. Resultados: Das variáveis que representam os andares superior e médio da face, apenas a variável VV:LS (verdadeira vertical: lábio superior) é significativamente diferente entre as duas populações. O lábio superior está mais avançado na população ideal do que na submetida a tratamento ortodôntico-cirúrgico. As variáveis que representam o andar inferior da face são praticamente todas diferentes entre as duas populações. Na amostra submetida a tratamento, a posição da mandíbula e dos tecidos moles continuam numa posição mais avançada no plano sagital, apesar da osteotomia sagital de recuo ter sido realizada. Conclusões: A população com má oclusão e má formação esquelética de classe III, apesar de ter sido submetida a tratamento ortodôntico-cirúrgico, continua com perfil prognático, com lábio superior recuado e com lábio inferior e mento avançados. Esta constatação alerta para as deficiências das análises cefalométricas com normas exclusivamente dento-esqueléticas.

http://doi.org/10.24873/j.rpemd.2019.12.634

\section{\#177 Atividade mitocondrial e antioxidante em doentes com diabetes mellitus e periodontite}

Fokt O.*, Ferreira I. L., Costa A. S., Baptista I. P., Rego A. C.

Instituto de Bioquímica da UC, CNC-Centro de Neurociências e de Biologia Celular, Universidade de Coimbra,

Departamento de Medicina Dentária, Faculdade de Medicina, Universidade de Coimbra

Objetivos: A periodontite é uma doença crónica e inflamatória, iniciada pela presença de um biofilme bacteriano que afeta os tecidos que suportam os dentes e culmina na reabsorção óssea. A diabetes mellitus (DM) é um grupo de doenças metabólicas caracterizada por uma hiperglicemia que induz um estado pró-inflamatório excessivo. Evidências atuais apontam para uma inter-relação bidirecional entre diabetes e periodontite, que se tornou conhecida como a sexta complicação da DM e pode ser um fator de risco para a descompensação diabética. Estas patologias associam-se ao stress oxidativo devido ao aumento da produção de espécies reativas de oxigénio (ROS).Assim, este trabalho teve como objetivo analisar a atividade do complexo III da cadeia respiratória mitocondrial, um importante produtor de ROS mitocondrial e a atividade enzimática e níveis proteicos de diferentes antioxidantes celulares utilizando células mononucleares do sangue periférico (PB$\mathrm{MCs}$ ) de doentes com periodontite crónica (CP), diabetes mellitus tipo 2 (DM) e DM com CP (DM-CP), quando comparados a indivíduos controlos. Materiais e métodos: Os doentes e indivíduos controlo foram selecionados através de consultas de Medicina Dentária no Centro Hospitalar da Universidade de Coimbra (CHUC), onde foram determinados os parâmetros clínicos para o diagnóstico da saúde periodontal. Resultados: Os resultados demonstram um comprometimento da atividade do complexo III (normalizado para a atividade da citrato sintase) e do ciclo do glutatião, nomeadamente uma redução das atividades das enzimas glutatião peroxidase, glutatião redutase e dos níveis de glutatião reduzido e oxidado, assim como uma tendência para uma redução na atividade da enzima superóxido dismutase de tipo 2 (SOD2/Mn-SOD) e dos níveis proteicos da isoforma peroxissomal da enzima catalase em doentes com DM e particularmente em doentes com DM-CP. Conclusões: Os resultados sugerem que a DM favorece um desequilíbrio da função redox devido ao défice da capacidade antioxidante em situações de periodontite crónica.

http://doi.org/10.24873/j.rpemd.2019.12.635

\#178 Experiência pedagógica com o recurso ferramentas colaborativas da Google

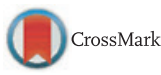

Maria João Ponces*, Eugénio Martins, Berta Meireles, Marta Jorge, Carlos Pires, Saúl Castro

Universidade de Trás-os-Montes e Alto Douro, Faculdade de Medicina Dentária da Universidade do Porto

Objetivos: Este estudo exploratório apresenta os resultados preliminares recolhidos a partir de dois questionários relacionados com uma experiência pedagógica instituída na unidade curricular de Tecnologias de Informação e Comunicação da Faculdade de Medicina Dentária da Universidade do Porto, cujo intuito principal foi promover competências com ferramenta colaborativas da Google através de um projeto conjunto com uma Instituição de Solidariedade Social. Organizados em grupos, os estudantes construíram um website ligado às páginas do Facebook, do Twitter e Instagram bem como uma newsletter. O objetivo deste estudo foi perceber o nível de utilização das ferramentas e o impacto que o projeto teve na aquisição de competências com as mesmas. Materiais e métodos: Os dados foram recolhidos a partir de dois questionários elaborados para o efeito e respondidos por 84 estudantes antes do início e 57 no final do projeto. Mediante o teste do Qui-quadrado, assegurou-se haver consistência na amostra que respondeu a ambos os questionários. Os questionários visa- 